\title{
Lessons from a student-led development project in Peru: Aligning technical and educational perspectives
}

\author{
Rachel Chisolm \\ Graduate Student, Department of Civil, \\ Architectural, and Environmental Engineering \\ University of Texas at Austin \\ Austin, TX 78712 \\ rachel.chisolm@gmail.com \\ Laura Read \\ Graduate Student, Department of Civil and \\ Environmental Engineering \\ Tufts University \\ Medford, MA 02155 \\ Laura.Read@tufts.edu
}

\author{
Elliott T. Gall \\ Postdoctoral Research Fellow \\ Nanyang Technological University \& \\ Berkeley Education Alliance for Research in Singapore \\ Singapore 138602 \\ elliott.gall@gmail.com \\ Fernando Renzo Salas \\ Graduate Student, Department of Civil, Architectural, and \\ Environmental Engineering \\ University of Texas at Austin \\ Austin, TX 78712 \\ fernando.r.salas@utexas.edu
}

Abstract - With the growth of student interest in humanitarian engineering development projects, a critical assessment of the strengths and weaknesses of this type of work is crucial to success. While a number of models exist for joining development with technical expertise in humanitarian engineering projects, this paper focuses on the experiences of students working on a program in Peru within the Greater Austin Chapter of Engineers Without Borders (EWB)-USA. This program is a unique EWB-USA program that builds on ongoing academic research in the Peruvian Andes at the University of Texas at Austin and regional efforts by The Mountain Institute to mitigate the effects of climate change on Peruvian communities that need technical solutions to water issues. We contrast the benefits and struggles of pursuing a student-led initiative with a regional scope. Specifically, this case study shares how the roles of partnerships between universities, private sector, government, and nongovernmental organizations create challenges and opportunities for a student-led humanitarian engineering program. The key challenges identified are (1) effectual use of U.S. team members, (2) building trust and open communication with in-country partners, and (3) understanding community dynamics and adapting projects to their local context. We present how development of a 'non-traditional engineering classroom' framework can serve as a proactive means for facilitating effective knowledge transfer, critical reflection, and service-learning to improve project outcomes.

Index Terms - Climate change adaptation, Engineers Without Borders, Design for developing countries, Non-traditional engineering classroom 


\section{INTRODUCTION}

The development framework of connecting U.S.-based technical expertise and resources with communities in developing countries is an increasingly popular model of participatory humanitarian engineering. ${ }^{i}$ This type of engineering requires engagement with stakeholders at many levels, ${ }^{\text {ii }}$ and engineers from diverse cultures face unique hurdles when collaborating. ${ }^{\text {iii }}$ Successful humanitarian engineering outcomes are most likely when development projects are undertaken with attention to community context, long-term sustainability, and well-designed monitoring and evaluation, ${ }^{\text {iv }}$

The concept of 'service-learning' in engineering education offers an opportunity for achieving technical success in humanitarian engineering while concurrently developing student leaders through active participation. Service-learning has been defined broadly as merging academic and practical experiences into an integrated pedagogy, ${ }^{\mathrm{v}}$ or in more specific terms as connecting service with structured courses and providing the space for critical reflection. ${ }^{\text {vi }}$ One such emergent model is a student-led humanitarian engineering program, which promotes service-learning by combining a 'traditional engineering classroom' in a university setting with experiences that go beyond the traditional academic course. Ideally, the strengths of field-based and classroom-based learning could be combined to support a holistic approach to humanitarian engineering by leveraging traditional engineering principles with site-specific social and technical knowledge. Passino (2009) describes a perceived need for engineering education initiatives that increase volunteerism in the engineering profession, and describe extracurricular organizations as offering an opportunity to apply a "theory-practice" approach to humanitarian engineering. ${ }^{\text {vii }}$

In this article, we focus on the student-led humanitarian engineering program model through the lens of a case study in the Peruvian Andes. In the student-led model the development and management of service-learning projects that concurrently enable growth of student leaders is likely a parallel outcome that accompanies technical project successes. Therefore, the purpose of this paper is to contribute a voice in the larger conversation on experiences from student-led humanitarian engineering programs by sharing successes and failures, and how the roles of faculty, students, and project partners are defined in a non-traditional service-learning environment. Specifically, this paper introduces how development of a non-traditional engineering classroom (NEC) can provide a framework for defining roles in a student-led program that is not necessarily linked explicitly to service-learning in the academic setting. This paper suggests that stakeholders be integrated into structured service-learning mechanisms to create formal space for critical interactive reflection. Benefits of service-learning for students are well established and range from improvements in problem-solving abilities, ${ }^{\text {viii }}$ oral and written skills ${ }^{\mathrm{ix}}$ to an overall sense of increased personal efficacy in students. ${ }^{\mathrm{v}}$ The reflections described in this work are informed by experiences and lessons learned derived from an ongoing program in Central Peru and are intended to help other programs consider new approaches for developing forward-thinking, socially-relevant international engineering projects in the context of their unique challenges and knowledge. Specifically, this case study focuses on the process of integrating various stakeholders in efforts towards a common goal of implementing solutions to local issues. 


\section{Program BaCkground}

The case study presented here is an on-going program started in 2011 under the framework of Engineers Without Borders-USA (EWB-USA), a non-profit organization whose mission is to develop sustainable programs that partner with and empower communities that lack access to basic human services. ${ }^{\mathrm{x}}$ EWB-USA mandates a minimum 5-year commitment to the community ${ }^{\mathrm{vi}}$ and has a formal reporting process by which project designs require approval by a Technical Advisory Committee (TAC) comprised of professional engineers and practitioners. ${ }^{\mathrm{x}}$

This program arose from graduate student involvement in ongoing faculty-led research at the University of Texas at Austin (UT-Austin) and was formally integrated into The Greater Austin Chapter of Engineers Without Borders (EWB-Greater Austin), which offers a platform to align humanitarian needs in Peru with demand from students and professionals seeking volunteer engineering opportunities. Since its founding, the program has created partnerships with international nongovernmental organizations (NGO), multinational corporations, and U.S. and Peruvian universities. While these partners have formed a valuable resource network for the program, managing disparate entities has produced considerable challenges.

\section{EWB-Greater Austin and the CAMBIAR Program}

EWB-Greater Austin is a combined student and professional chapter whose average membership of 50-80 active members is predominantly made up of students from UT-Austin and professional engineers in the Greater Austin metropolitan area, though is not formally affiliated with UTAustin due to the existence of a service-learning class. ${ }^{\mathrm{xi}}$ One reason for this is that UT-Austin is constrained by the academic calendar and EWB-USA has a 5-year commitment to communities, both UT-Austin and EWB-Greater Austin operate independently without a formal partnership.

In May 2011, EWB-Greater Austin started a program in Ancash, Peru to work with communities in the Andean region on climate change adaptation projects. As such, the EWBGreater Austin program in Peru created the Climate Adaptation in Mountain Basins in the Andean Region (CAMBIAR) program, "cambiar" meaning "to change" in Spanish. Over the past three years CAMBIAR has become a larger initiative in which the EWB-Greater Austin program is one of several components. A summary of the involved stakeholders and primary roles and responsibilities for all stakeholders can be found in Table I.

EWB-Greater Austin initiated CAMBIAR in conjunction with two Peruvian organizations: The Mountain Institute (TMI) and the Tres Cuencas Commonwealth (Commonwealth). TMI is an NGO focused on "conserving mountain ecosystems, preserving mountain cultures and developing sustainable mountain economies." ${ }^{x i i}$ The Commonwealth referred to here is a group of municipalities and districts within Ancash who have formed a collective entity to manage local water issues within its three watersheds (cuencas); see Figure 1 for a map of the Commonwealth extent. The benefit in formalizing a commonwealth structure in Peru is that larger-scale (regional) projects receive preference in public funding, thus a collective of 19 communities is more likely to be awarded funds for addressing a common problem than is a single community. In this way, the Commonwealth provides its individual communities with an essential mechanism to collectively solicit financial resources for acting on a regional issue.

The CAMBIAR framework has been organized around EWB-Greater Austin, TMI, and the Commonwealth with each partner supporting the program in a unique capacity. TMI supports the program by providing (1) logistical support for EWB-Greater Austin trips (2) social and geo- 
political insight for EWB-Greater Austin (3) organization of workshops and training materials for Commonwealth communities, and (4) facilitation of communication between EWB-Greater Austin and Commonwealth communities via e-mail, telephone and formal letters. The role of the Commonwealth is to (1) coordinate needs assessments within communities (2) organize municipality support for individual projects and (3) provide a means for transferring project knowledge and expertise between communities.

\section{TABLE I}

KEY STAKEHOLDERS IN THE CAMBIAR INITIATIVE

\begin{tabular}{|c|c|c|}
\hline Stakeholder & Abbreviation & Role \\
\hline $\begin{array}{c}\text { Climate Adaptation in } \\
\text { Mountain Basins in the Andean } \\
\text { Region }\end{array}$ & CAMBIAR & $\begin{array}{l}\text { Help the Commonwealth realize strategies to conserve and } \\
\text { more efficiently manage their water and to equip } \\
\text { Commonwealth residents with the knowledge, means, and } \\
\text { tools to build resilience to climate change }\end{array}$ \\
\hline \multicolumn{3}{|l|}{ Local Stakeholders in Peru } \\
\hline The Mountain Institute & TMI & $\begin{array}{l}\text { Provide on-the-ground support for CAMBIAR efforts } \\
\text { through communication, education, and management of the } \\
\text { social aspect of projects }\end{array}$ \\
\hline Tres Cuencas Commonwealth & Commonwealth & $\begin{array}{l}\text { Facilitate CAMBIAR activities at the commonwealth level, } \\
\text { assist in identifying needs of individual communities, and } \\
\text { provide a platform for knowledge transfer and upscaling of } \\
\text { pilot technologies }\end{array}$ \\
\hline Municipality of Huasta & Municipality & $\begin{array}{l}\text { Support projects at the local level through logistical and } \\
\text { financial assistance; facilitate communication between the } \\
\text { community and the Commonwealth to promote knowledge } \\
\text { transfer }\end{array}$ \\
\hline $\begin{array}{c}\text { Campesina Community of } \\
\text { Huasta }\end{array}$ & $\mathrm{CC}$ & $\begin{array}{c}\text { Provide local project support through coordination of } \\
\text { logistics, garnering community based support and manual } \\
\text { labor }\end{array}$ \\
\hline \multicolumn{3}{|l|}{ U.S.-based Stakeholders } \\
\hline $\begin{array}{c}\text { Engineers Without Borders- } \\
\text { USA }\end{array}$ & EWB-USA & $\begin{array}{l}\text { Provide oversight in the project process and ensure } \\
\text { adherence to EWB-USA's principles of development and } \\
\text { technical design standards }\end{array}$ \\
\hline $\begin{array}{c}\text { Greater Austin Chapter of } \\
\text { EWB-USA }\end{array}$ & $\begin{array}{l}\text { EWB-Greater } \\
\text { Austin }\end{array}$ & $\begin{array}{l}\text { Provide technical expertise to Commonwealth communities } \\
\text { in the form of needs assessment and design and } \\
\text { implementation of small-scale infrastructure }\end{array}$ \\
\hline $\begin{array}{c}\text { The University of Texas at } \\
\text { Austin }\end{array}$ & UT-Austin & $\begin{array}{c}\text { Offer courses with relevant academic curricula including an } \\
\text { existing service learning course, facilitate connections } \\
\text { between EWB-Greater Austin and TMI; provide a } \\
\text { consistent presence of faculty and graduate student } \\
\text { researchers in country }\end{array}$ \\
\hline Tufts University & Tufts & $\begin{array}{l}\text { Pilot and provide technical support for the mobile data } \\
\text { collection program; introduce a second student network to } \\
\text { support additional research }\end{array}$ \\
\hline
\end{tabular}


CAMBIAR intends to support simultaneous projects depending on the needs outlined by the Commonwealth and resources available from all parties. In August 2011, the Commonwealth suggested Huasta be the first community for an EWB-Greater Austin project. Huasta is a district located in a tributary of the Pativilca River valley in Ancash, Peru and is governed by the mayor of the Municipality. A large portion of the land and residents of Huasta belong to a community land-owners' association known as the "Campesina Community" (CC) of Huasta, an example of a farmers cooperative formed during the land reform of the 1970's. ${ }^{\text {xii }}$ The CC exerts significant influence on the Municipality and regularly lobbies for funds for agriculture, reported by the CC as the primary concern of community members in Huasta. ${ }^{\text {xiv }}$

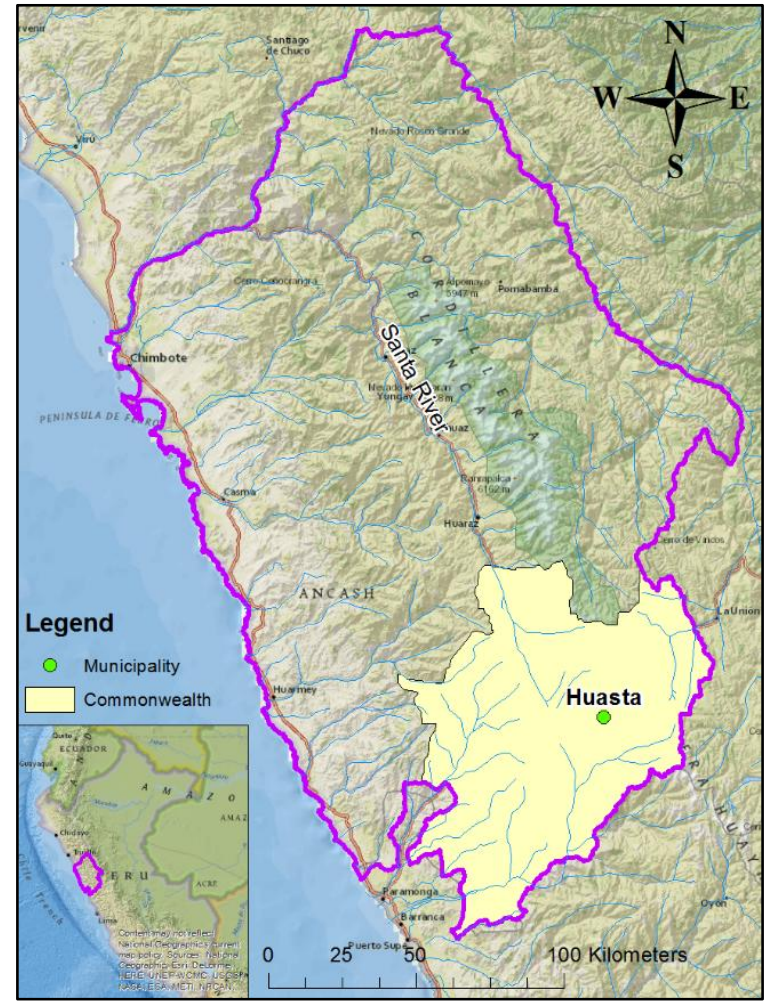

FIGURE 1

OVERVIEW OF REGION DEPICTING THE REGIONAL EXTENT OF THE TRES CUENCAS COMMONWEALTH INLAY: LOCATION WITHIN PERU

\section{Pilot Projects: Wastewater Treatment Plant and Pasture Irrigation System}

In January 2012, EWB-Greater Austin traveled to Huasta on an assessment trip to evaluate the needs of the CC. Determined through a series of meetings and interviews, the CC's most desired project was reuse of effluent from a municipal wastewater treatment plant (WWTP) for yearround irrigation of a community-owned pasture to support an expanded livestock operation. After a year of data collection, testing, observation, and planning with the Municipality and CC, EWB-Greater Austin, in conjunction with the EWB-USA TAC, determined that the effluent 
from the WWTP did not meet international standards for livestock irrigation; this was a result of poor maintenance and operation of the WWTP, a common problem with existing WWTPs in rural Peru. ${ }^{\mathrm{XV}}$ As a result, EWB-Greater Austin supported a technical education project with the following outcomes: (1) a comprehensive technical assessment of the plant - from the original drawings and capacities to the current problems and outflow quality - that was delivered to the municipality by the EWB-Greater Austin team with the assistance of several local Peruvian wastewater engineers, and (2) a detailed operation and maintenance manual for the municipality to train workers for following standard operating procedures. In addition to these tangible products, the WWTP project brought awareness to residents of Huasta regarding mismanagement of the plant and the need for expertise and resources to improve conditions.

In January 2013, EWB-Greater Austin again traveled to Huasta to continue efforts towards irrigating the community pasture and discovered two springs upstream that were later developed for use in supplying the sprinkler irrigation system. This system design was implemented in July 2013 and January 2014; the CC and EWB-Greater Austin worked together to build the physical infrastructure for the irrigation system and train $\mathrm{CC}$ members in operation and maintenance.

Technical outcomes from the irrigation project are on-going. To date, the project has led to (1) construction of two source spring boxes, (2) installation of a one kilometer pipeline from source to field, (3) installation of a sprinkler system, and (4) design of a sprinkler system and rotation schedule for delivering adequate water based on crop demand. The EWB-Greater Austin team is in the process of monitoring improvements in water use efficiency compared to typical flood irrigation practices. Because a number of Commonwealth communities struggle with climate change impacts on water availability and insufficient agriculture water in the dry season, the Huasta irrigation pilot project has raised awareness for sprinkler technology to serve as a possible solution for other communities.

\section{Research partnerships}

CAMBIAR cooperates with graduate level research supported by educational institutions (UTAustin and Tufts) and USAID. One such effort, primarily funded by USAID and secondly by Tufts University, is the development and pilot of a mobile app to collect water and climate data in rural communities. ${ }^{x v i}$ This type of monitoring effort goes beyond the currently limited observational monitoring technologies and practices in typical student-led engineering projects, and has been made possible by the diversity of partners involved in the project and the academic expertise of graduate students and faculty at Tufts. Since entering the pilot phase in summer 2014, the mobile app project has developed flexible software for community members, students, and organizations to utilize depending on their specific needs (i.e. water quality, streamflow, etc.), set up an internet database for recording and publishing the information, and identified participants and locations for testing. Participatory science research that engages community members in research and data collection has been considered one way to connect servicelearning and research to aid knowledge transfer. ${ }^{\text {xvii, }}$ xviii, xix Further integrating research and development will enable long-term partnerships between international partners and U.S. by creating shared goals. TMI is co-leading the expansion of this pilot phase by supporting local Peruvian university students to use the mobile app where appropriate in their research projects.

Involvement of Tufts and UT-Austin has been key to expanding the CAMBIAR initiative beyond EWB-Greater Austin. Tufts has two institutional resources - Tisch Citizen College and Tufts Institute of the Environment - that the CAMBIAR program utilized for funding students to 
travel and conduct research. These students were undergraduate non-engineers (environmental policy) and graduate water resources engineers interested in water, climate change, and stakeholder-driven solutions. Their participation has added diversity to the CAMBIAR team's efforts and helped promote a more interdisciplinary perspective in the projects. In addition to students benefitting from exposure to an international setting and service learning, Tufts benefits by increasing its network of active research projects to include more on-the-ground humanitarian work in university education and academic research.

CAMBIAR has worked with TMI and UT-Austin to seek research grants that unite the missions of all parties. TMI has recently acquired funding for a 3-year USAID project (Securing Mountain Water and Livelihoods) that is focused on developing relationships between stakeholders interested in seeking climate change adaptation solutions. The close alignment of this project allows CAMBIAR activities to fall under the umbrella of the USAID project, providing the resources for TMI to fully support EWB-USA projects for at least the next three years and greater integration of UT-Austin research activities with the service-learning objectives of CAMBIAR.

\section{Challenges AND Lessons Learned}

Critical reflection on the effectiveness of "remote" humanitarian engineering is an important, and often overlooked aspect of student-led programs in international development. ${ }^{\mathrm{xx}}$ Many challenges of student-led programs in international development derive from difficulties associated with undertaking engineering projects from a distance. Challenges only become lessons learned if there is critical reflection that leads to improvements in the way projects are undertaken. This section discusses some of the key challenges that CAMBIAR has faced and the conclusions taken from those lessons that have altered the project approach. Most of these lessons have led to careful consideration of the role of stakeholders, how they are incorporated into the project, and how they can contribute to the non-traditional education of engineering students working on CAMBIAR projects; these lessons are summarized in Table II.

\section{Integration within EWB-USA}

One important benefit of managing the CAMBIAR program through EWB-USA is access to formal mechanisms of accountability and feedback that may have been otherwise absent or patchwork. The EWB-USA framework has supported the appropriate implementation of projects through required checkpoints and reviews. Specific examples of accountability mechanisms are pre- and post-site visit reporting requirements, the Planning, Monitoring, Evaluation and Learning (PMEL) program, and evaluation by a EWB-USA project engineer and TAC. ${ }^{\mathrm{x}}$

While EWB-USA has compliance programs in place, quality control at the chapter level is a necessary component for every project. One chapter responsibility in need of greater attention is developing a culture in which individuals and project members feel they can openly report risks, both in safety and project delivery. Since members are passionate about project completion, it can be challenging to change the mentality that the project must progress, no matter the risk or potential adverse impacts. This sort of cultural shift must take place at the chapter-level and be supported by mentorship by both professional members and faculty. A crucial lesson in practical engineering is teaching students how to recognize when to reevaluate a project and either change the project course or terminate the project if there are significant problems. One example of this 
is the decision to shift the Huasta project from focusing on the WWTP to the irrigation system with new water sources due to fundamental problems with the design of the WWTP and the ownership and management system.

\section{TABLE II}

\section{LESSONS LEARNED DURING THE EVOLUTION OF CAMBIAR PROGRAM}

\begin{tabular}{|c|c|}
\hline Category & Lesson Learned \\
\hline $\begin{array}{l}\text { Integration within } \\
\text { EWB-USA }\end{array}$ & $\begin{array}{l}\text { Integrate EWB-USA technical, safety and accountability standards at the chapter and } \\
\text { individual level to reinforce quality control at the national level }\end{array}$ \\
\hline \multirow{2}{*}{$\begin{array}{l}\text { University } \\
\text { partnerships }\end{array}$} & $\begin{array}{l}\text { Set feasible expectations for faculty involvement and leadership: day-to-day level may be } \\
\text { unrealistic, but faculty can oversee critical reflection and documentation of lessons } \\
\text { learned }\end{array}$ \\
\hline & $\begin{array}{l}\text { Cultivate long-term, high-level partnerships with University faculty in a tangible, specific } \\
\text { way }\end{array}$ \\
\hline \multirow{2}{*}{$\begin{array}{l}\text { Open } \\
\text { communication }\end{array}$} & $\begin{array}{l}\text { Develop a mechanism to gather the true opinions of the community; NGO should play a } \\
\text { key role }\end{array}$ \\
\hline & Invest in activities to build trust with the community and facilitate open communication \\
\hline \multirow{2}{*}{$\begin{array}{l}\text { Understanding local } \\
\text { processes }\end{array}$} & $\begin{array}{l}\text { Adapt project teams' decision-making process and timeline to align with that of the } \\
\text { community; communication of protocols by both the community and EWB-USA is } \\
\text { essential }\end{array}$ \\
\hline & $\begin{array}{l}\text { Make a commitment to understanding community dynamics, local politics, and pathways } \\
\text { for flexibility within the project timeline and adapting the project accordingly }\end{array}$ \\
\hline
\end{tabular}

\section{University and faculty partnerships}

The university context can facilitate project success by adding project accountability, reflection, and learning outcomes. ${ }^{\text {xxi }}$ Since $72 \%$ of EWB-USA members are housed in university student chapters and the majority of these members are students, ${ }^{x x i i}$ it is important to reflect on the interaction between students and faculty within the context of a humanitarian engineering program. Academic research and education at the undergraduate and graduate levels, can lead to improved project and educational outcomes ${ }^{\text {xxiii }}$ and also present an opportunity for achieving deeper faculty involvement.

According to Beadle (2014), faculty involvement appears to be limited in many EWB-USA chapters. ${ }^{\text {xii }}$ A survey of 534 students who recently completed international projects through EWB-USA found students self-rated faculty involvement as the least important of seven primary inputs in determining project outcomes. ${ }^{\text {xxii }}$ This is likely a result of infrequent participation; Beadle (2014) reports that $37 \%$ of faculty advisors attended project meetings 'never or less than once per month' compared to $17 \%$ and $29 \%$ of students and professional mentors, respectively. ${ }^{\text {xii }}$ Perhaps most tellingly, a statistical analysis of survey responses showed only weak correlations between reported faculty advisor inputs and self-reported scores of student learning success. In spite of this, students appear satisfied with this state of the role of faculty, indicating in focus groups that no changes should be made regarding faculty advisors. ${ }^{\text {xii }}$

Although these results suggest project success is not dependent on faculty involvement, a number of studies cite the 'cycle of action' and reflection as critical to the success of student-led humanitarian engineering and service-learning programs. ${ }^{x x i v, ~ x x v, ~ x x v i, ~ x x v i i ~} A n$ inevitable factor in 
student led programs is a yearly turnover of project members that causes difficulty in the creation of institutional knowledge and heightens the need for formal mechanisms of reflection and documentation. University faculty are uniquely suited to formally integrate this cycle into EWBUSA programs. By applying their training and practice in pedagogy, university faculty can oversee and facilitate discussion on successes and failures in socio-technical contexts. By leveraging experience in documenting and disseminating knowledge in archival journals, faculty can apply best practices in ensuring learning is preserved and transmitted to incoming student project members. University faculty may also be well suited to help create custom curricula, similar to a traditional engineering class, based on lessons learned and project outcomes. The commitment of Universities to higher ideals of scholarship and global citizenship are also wellaligned with the need to consider project outcomes in social, economic, and political contexts. Recognizing the value of faculty in humanitarian engineering programs, CAMBIAR has sought to involve faculty through research outlets since EWB-Greater Austin is not formally aligned with a University. However, developing informal faculty relationships has been a challenge and thus one of the benefits of the USAID grant is a more aligned relationship with UT-Austin faculty. Furthermore, CAMBIAR members have also been encouraged to take advantage of educational opportunities that UT-Austin offers to provide a technical basis for executing international humanitarian engineering projects.

\section{Seeking open communication}

Participatory humanitarian projects are typically small scale and technically straightforward, but community buy-in and participation remain essential for a project's success. One of the challenges for CAMBIAR projects is learning to gauge community buy-in when the EWBGreater Austin team only visits the community one to two times per year. Community members are often reluctant to speak openly with foreigners whom they do not know and initially may not trust. For example, the manner in which questions are asked can potentially shift the results of an assessment to favor the project the EWB-USA team thinks would be most beneficial, rather than what the local community actually needs or prioritizes. Another example of communication challenges is a cultural tendency to avoid conflict that may prevent the community from being forthcoming about potential problems. The EWB-Greater Austin team was initially told that the downstream effect of capturing spring water and diverting it for irrigation would not be an issue, but it was only made known to the team just before implementation that some community members do use the surface water runoff from the spring source for irrigation, a potential source of conflict unknown to the EWB-Greater Austin team. Although this was not a major problem because the design was altered to allow diversion for the downstream user, thus satisfying everyone, it is important to understand all potential problems and sources of conflict before implementing a project.

To avoid negative impacts arising from poor communication, a better mechanism for gauging the community's true opinions about a project must be developed. Due diligence must extend beyond the scope that many students are trained in, i.e., a student in a classroom will generally ask a targeted question and receive a response that he/she can take to be true. Field research and Water, Sanitation, and Hygiene (WASH)-focused organizations use techniques such as focus groups, pocket diagrams, and three-pile sorting activities to solicit behaviors and opinions from community members without directing questioning. ${ }^{\text {xviii }}$ Open communication is a challenging aspect of any humanitarian engineering project, particularly given different communication 
styles and cultural expectations. The direct communication style of U.S. engineers is in contrast with a tendency in Latin America for indirect communication. A committed in-country NGO partner can play an integral role in facilitating communication and a common language and understanding between the parties based on their deeper knowledge of the local culture and attitudes and play a role in teaching engineering students how to understand a culture different from their own, learn from sub textual clues the community may be giving them, and employ new styles of communication. This type of NGO partner can also facilitate informal encounters with a community like sharing meals, exploring the area's hiking trails, and other opportunities to build trust on a personal level. In the modern age of technology, distance and virtual communication is easier and more economical than ever, but a common language and understanding must be present for an effective collaboration between all stakeholders.

\section{Understanding local processes}

Needs assessments of in-country partner communities are facilitated or limited by internal community dynamics and external stakeholder communication. As communities evolve, so too must the approach of U.S.-based partners. EWB-USA project teams also have a responsibility to educate partner communities on the EWB-USA process and protocols. Communities are not accustomed to the multi-year timeline typical of EWB-USA projects, and such a long delay between assessment, design, and implementation can contribute to a loss of faith unless a mutual understanding is established between the community, NGO partner, and EWB-USA team.

Within Commonwealth communities, it is common for the municipal government and the CC to operate in parallel, providing logistical challenges because it can be unclear where the project ownership ultimately lies. An additional challenge is that decisions made by the $\mathrm{CC}$ must be made by consensus, and, at present, this has prevented the planting of any crop and delayed use of the Huasta irrigation system project. Leadership from both entities can help project teams navigate the complex political landscape and ensure that project ownership and responsibilities are appropriately allocated. One of the reasons CAMBIAR decided not to proceed further with the WWTP was the issue of ambiguous responsibility. The WWTP is owned and operated by the Municipality, but the Municipality was unable to take responsibility for ensuring the quality of the effluent. The CC was also unable to take over the WWTP cleanout, rehabilitation, and regular maintenance; and, because of this breakdown in the chain of operations the project was unable to progress. Setbacks due to local government and community dynamics must be considered part of the project process, but if community partners take an active role in instructing student teams on local protocols and customs, decisions about project direction can be made more quickly and effectively. Equally it is the project teams' responsibility to prioritize understanding these local mechanisms.

The increasing prevalence of fractured group dynamics in many Andean communities means that CAMBIAR should reevaluate its process and objectives, and perhaps the 'community unit' should be redefined to better reflect the dynamics that may exist and impact the project process. Development approaches should evolve as a culture evolves, and new methods should be sought for engaging communities in need within the socio-political context of the community. For this to happen, the NGO must help inform the project team on the local community decision-making dynamics. 


\section{DISCUSSION: ROLES AND RESPONSIBILITIES IN A NON-TRADITIONAL ENGINEERING ClaSSROOM}

Student-led humanitarian engineering programs are composed of complex, evolving, and asymmetric relationships. The framework for facilitating interaction between partners within a service-learning environment may often manifest as reactive and created in response to shortterm needs rather than a structured proactive process. To address the challenges discussed from the bottom-up, the authors suggest that student-led programs give attention to building a custom non-traditional service-learning environment. In this conceptual framework, student leaders can leverage expertise of US and international partners to develop a supportive environment that actively promotes service-learning, while also increasing the likelihood of a successful project through a 'non-traditional engineering classroom' (NEC). In the NEC, student leaders, seasoned faculty, and professionals must be adaptable; faculty and professionals should offer their expert guidance and opinions informed by the evolving state of knowledge derived from project efforts. Essentially, the envisioned NEC is an implementation of a $21^{\text {st }}$ century paradigm of teaching as described by Tucker et al. (2014), where students are viewed as 'problem solvers' and faculty, and in this case professional mentors and international partners, engage in peer to peer relationships with students as both 'coaches and facilitators. ${ }^{x x}$ In fact an element of the NEC is to develop university courses that focus on service-learning objectives and partner with studentled engineering programs like EWB-USA chapters to offer a more structured project process.

The key partners to consider in the NEC are: the governing non-profit/institution (in this case EWB-Greater Austin and EWB-USA), University faculty, professional members, student members, and international partners including in-country NGOs and partner communities. Table III describes key opportunities and the proposed role of each stakeholder in the proposed NEC.

This case study of the CAMBIAR program considers management of personnel from the viewpoint of student leaders in the EWB-Greater Austin chapter. Regardless of the entity leading the program, the concept of an NEC is intended to enable student leaders to proactively manage their project team, partners, and the learning experiences of all parties. One goal of the envisioned NEC is to empower student project leaders to effectively integrate faculty and professional members into projects where students, either by design or by default, lead international development projects. This section details how an NEC can help define these roles for various stakeholders and address the challenges raised in building a student-led humanitarian engineering program. 
TABLE III

ROLES IN A NON-TRADITIONAL ENGINEERING CLASSROOM

\begin{tabular}{|c|c|}
\hline Stakeholder & Role in non-traditional engineering classroom \\
\hline CAMBIAR/EWB-Greater Austin & $\begin{array}{c}\text { Oversee management of program and integration of stakeholders into } \\
\text { NEC; define roles and solicit requests for expertise from US and } \\
\text { international stakeholders; professional engineers in oversight roles }\end{array}$ \\
\hline EWB-USA & $\begin{array}{c}\text { EWB-USA's reporting mechanisms adds necessary accountability in } \\
\text { NEC; utilize EWB-USA resource (e.g., online knowledge base, } \\
\text { personnel, conferences) }\end{array}$ \\
\hline University Partnership & $\begin{array}{c}\text { Faculty are uniquely qualified to lead efforts that result in critical } \\
\text { learning and reflection; greater integration of research into service- } \\
\text { learning projects may facilitate deeper faculty involvement }\end{array}$ \\
\hline The Mountain Institute/NGO Partner & $\begin{array}{c}\text { Provide on-the-ground knowledge, and up to date information. NGO } \\
\text { plays a crucial role in understanding community dynamics }\end{array}$ \\
\hline Huasta Community & $\begin{array}{c}\text { Educate EWB-USA members on their customs and protocols, make } \\
\text { priorities clear, and actively participate in all phases of the project }\end{array}$ \\
\hline
\end{tabular}

Undergraduate students are typically the drivers of U.S.-based efforts, as their motivation creates a critical mass of support and awareness for project fundraising and short-term logistical and technical needs. As discussed previously, turnover is a concern in student-led programs, where knowledge and project continuity are often lost as students graduate. In a non-traditional engineering environment graduate students may be suited to assist or lead engagement of undergraduates, by virtue of training under faculty direction and pursuit of independent research, and thus can serve as bridges between undergraduates and faculty.

Technical project outcomes, e.g., construction of water conveyance infrastructure, fall squarely in the purview of professional members. Thus, the expertise of professional members, often consulting engineers with design experience, licensure, and project management expertise should complement faculty mentorship in the NEC. The EWB-USA guidelines in place for professional mentors who sign on as 'engineers in charge' align well with the NEC mission.

The role of university faculty in the NEC is to lead pedagogical and knowledge transfer efforts. Faculty involvement can be increased by defining a tangible role, for example with a targeted request to assist with critical reflection and learning. Time constraints likely limit faculty involvement; in a non-traditional environment, faculty-led research is linked with humanitarian engineering goals to allow deeper engagement by faculty and graduate students in these programs. This has been true for CAMBIAR, where on-going student and faculty research provided support for more frequent site visits by student researchers, increasing communication with the in-country NGO partner.

The role of international partners in an NEC is as to mentor and facilitate in the project process. As previously discussed, international stakeholders play a key role in many nontechnical aspects of a project that are often more critical to success than the technical design. The skills required to assess community dynamics are not generally taught in the traditional engineering curriculum, and engineers must often go beyond their experience to look for ways to gain a comprehensive view of the context in which the project will be implemented. ${ }^{\mathrm{xxxi}}$ Working closely with in-country partners can provide a learning environment that teaches engineering 
students the soft skills required for a successful project. By engaging multiple in-country partners and stakeholders as unofficial instructors in the communication and planning skills needed to make a well-rounded and effective engineer, a NEC may offer an effective service-learning platform that diversifies the education of engineering students and helps to prepare them for the post-graduation workplace.

\section{CONCLUSIONS}

CAMBIAR provides a case study for analyzing a student-led humanitarian engineering program with respect to the challenges in creating a sustainable project with a remote community while engaging U.S. and international partners as stakeholders. Many of the lessons CAMBIAR has learned about engaging and understanding local communities can be applied to any EWB-USA project. Each individual project can be strengthened by the knowledge and experience gained by others, and with a deeper understanding of the local culture and context, EWB programs within CAMBIAR can grow to be stronger than several independent EWB-USA projects. Reflecting on the CAMBIAR program, many limitations can be addressed through intentional design and proactive management of a 'non-traditional engineering classroom', where student leaders engage experts and international partners to ensure that site-specific project knowledge is gathered, disseminated, critiqued, and institutionalized into the project. Despite efforts to learn from past mistakes and shortcomings, some of CAMBIAR's challenges remain unsolved. While it is important to acknowledge these difficulties and attempt to mitigate potential problems, they should not prevent students from continuing to work on humanitarian engineering projects as long as the project is in line with the goals of the community and partners, and sharing lessons learned. Honest acknowledgment of deficiencies and limitations can ultimately promote more sound and successful projects.

\section{CONTRIBUTORS}

All authors contributed equally to the writing and editing of the article.

\section{ACKNOWLEDGMENT}

The authors would like to thank the EWB-USA staff, especially Kelly Latham for her mentorship, and members of EWB-USA, EWB-Greater Austin and the CAMBIAR program for providing the facility and leadership to execute the aforementioned projects. The authors would also like to thank Dr. Jorge Recharte and the TMI staff, Dr. Daene McKinney and professors within the Environmental and Water Resources Engineering department at UT-Austin, Dr. Guy Fipps at Texas A\&M University, USAID, UNASAM, Coseppi Partnership for their in-kind support, and Andrea Ryan for her comments and editing. Finally, the authors would like to thank the Notre Dame-Global Adaptation Institute, Tufts Institute for the Environment, Tisch College at Tufts University, ERM, Boeing, CDM-Smith, CH2MHill, Exxon and BP for funding the CAMBIAR program. 


\section{REFERENCES}

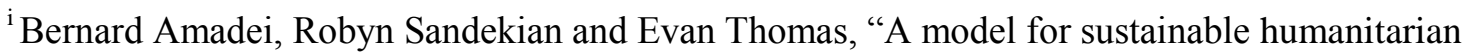
engineering projects,” Sustainability (2009), 1, 1087-1105.

ii Thomas H. Colledge, "Convergence: Philosophies and Pedagogies for Developing the Next Generation of Humanitarian Engineers and Social Entrepreneurs," International journal for service learning in engineering (2012).

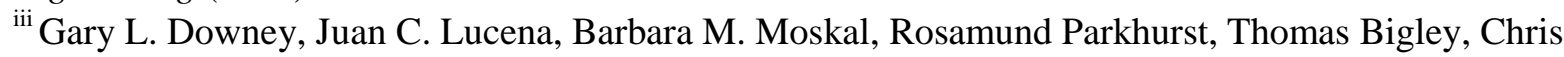
Hays, Brent K. Jesiek, Liam Kelly, Jonson Miller, Sharon Ruff, Jane L. Lehr and Amy Nichols-Belo, "The Globally Competent Engineer: Working Effectively with People Who Define Problems Differently," J. Eng. Educ (2006), 95, 107-122. doi:10.1002/j.2168-9830.2006.tb00883.x. ${ }^{\text {iv }}$ Ghazala Mansuri and Vijayendra Rao, "Community-Based and -Driven Development: A Critical Review," World Bank Res. Obs. (2004) 19, 1-39. doi:10.1093/wbro/lkh012.

${ }^{v}$ Alexander W. Astin, Lori J. Vogelgesang, Elaine K. Ikeda, and Jennifer A. Yee. How service learning affects students. Los Angeles, CA: Higher Education Research Institute, University of California, 2000.

${ }^{v i}$ Susan J. Deely "Service-learning: Thinking outside the box." Active Learning in Higher Education 11, no. 1 (2010): 43-53.

${ }^{\text {vii }}$ K.M. Passinio, "Educating the humanitarian engineer" Science and Engineering Ethics (2009) 15(4), 577-600.

viii J. Eyler, "Reflection: Linking Service and Learning - Linking Students and Communities." Journal of Social Issues (2002) 58(3), 517-534.

${ }^{\text {ix }}$ Meta Mendel-Reyes. "A pedagogy for citizenship: Service learning and democratic education." New Directions for Teaching and Learning 1998, no. 73 (1998): 31-38.

${ }^{\mathrm{x}}$ EWB-USA, Engineers Without Borders-USA Annual Report. EWB-USA: Denver, CO, 2013.

xi "Projects for Under-Served Communities," accessed December 18, 2014, http://world.utexas.edu/puc.

xii "The Mountain Institute: Conservation. Culture. Community.," accessed September 25, 2014, http://www.mountain.org/.

${ }^{x i i i}$ R. Maria Saleth, "Land Reform Under Military: Agrarian Reform in Peru, 1969-78," Economic and Political Weekly (1991), Vol. 26, Issue: 30, Pages: PE85-PE92.

${ }^{x i v}$ P. Dourojeanni and F. Zapata, Linea de Base: Comunidad Campesina de Huasta. The Mountain Institute, 2011.

${ }^{\mathrm{xv}}$ Wilson Novoa Mirande, personal communication, Huasta, Peru. July 2012.

${ }^{\text {xvi }}$ C. S. Lowry and M. N. Fienen, "CrowdHydrology: Crowdsourcing Hydrologic Data and Engaging Citizen Scientists," Ground Water (2013), 51, 151-156, doi:10.1111/j.1745-6584.2012.00956.x.

xvii J. Stilgoe, "Citizen Scientists - Reconnecting science with civil society," (2009) Demos, London, ISBN 97819066930 12, http://www.demos.co.uk/files/Citizen_Scientists_-_web.pdf.

xviii J. Lubchenco, "Entering the century of the environment: a new social contract for science," Science (1998) 279.

${ }^{\text {xix }}$ P. Graff, E. Dahlin, C. Ward and R. Lewis, "Analysis of integrated engineering and social science approaches for projects in developing communities." Int. J. Serv. Learn. Eng. (2013), ISSN 1555-9033, 137-150.

${ }^{\mathrm{xx}}$ Damberger, "Learning from failure," TED $x$ YYC, 2011.

${ }^{x x i}$ C. Palacios, "Volunteer tourism, development and education in a postcolonial world: Conceiving global connections beyond aid." Journal of Sustainable Tourism (2010) 18(7), 861-878. 
${ }^{x x i i}$ R.A. Beadle, "Building a Better World: Evaluating Student Perceptions of Programmatic Inputs and Outcomes on Engineers Without Borders-USA Projects" MPS 593 Integrative Seminar, DePaul University (2014) Report to EWB-USA.

${ }^{x x i i i}$ Bernard Amadei and Robyn Sandekian, "Integrating sustainable community development in engineering education," Proceedings of the 14th annual conference of the National Collegiate Inventors and Innovators Alliance, San Francisco, March 25-27, 2010.

${ }^{\text {xxiv }}$ A. Aslam, I. Navarro, A. Wen, M. Hassett, R.J. Swap, "Stuck in Cement: Breaking from Conventional Mindsets in Student-Led Service Learning Partnerships." International Journal for Service Learning in Engineering (2014) 9(2), 135-149.

${ }^{\mathrm{xxv}}$ H.N. Bischel, E.R. Sundstrom, "5-year evaluation of a course model for student initiated engineering service learning" International Journal for Service Learning in Engineering (2011) 6(1), 1-13.

${ }^{x x v i}$ Eyler, Janet S. "What Do We Most Need To Know about the Impact of Service-Learning on Student Learning?." Michigan Journal of Community Service Learning (2000).

${ }^{x x v i i}$ B.W. Speck, "Why Service-Learning?" New Directions for Higher Education (2001) 114, 3-13.

${ }^{x x v i i i}$ A. M. Almedom, U. Blumenthal and L. Manderson, "Hygiene evaluation procedures: approaches and methods for assessing water (and sanitation) related hygiene practices." International Nutrition

Foundation for Developing Countries (1997).

xxix Vidal Rondán Ramírez, personal communication. Huaraz, Peru. August 26, 2014.

${ }^{x x x}$ B.G. Tucker, D.O. Kazmer, A.R. Bielefeldt, K. Paterson, O. Pierrakos, A. Soisson, "The reflective learner: Perspective of engineering faculty engaged in learning through service" International Journal for Service Learning in Engineering (2014) 9(2), 29-46.

${ }^{x x i}$ D. Nieusma and D. Riley, Are Engineers Competent to Undertake Development Work? PE, October 2010. 